\title{
XXXI. General curves for the velocity of complete homogeneous reactions between two substances at constant volume
}

\author{
George W. Todd D.Sc. B.A.
}

To cite this article: George W. Todd D.Sc. B.A. (1918) XXXI. General curves for the velocity of complete homogeneous reactions between two substances at constant volume, Philosophical Magazine Series 6, 35:207, 281-286, DOI: 10.1080/14786440308635762

To link to this article: http://dx.doi.org/10.1080/14786440308635762

曲 Published online: 08 Apr 2009.

Submit your article to this journal $₫$

Џll Article views: 2

Q View related articles $\sqsubset$ 


\section{[ 281 ]}

XXXI. General Curves for the Velocity of Complete Homogeneous Reactions between Two Substances at Constant Volume. By George W. Todn, D.Sc.(Birm.), B.A. $(\text { Camb. })^{*}$.

\section{[Plate IX.]}

WHEN $m$ molecules of a substance $\Lambda$ react with $n$ molecules of a substance $B$ to give one or more resultants, there being no back reaction, the velocity of the reaction is given by

$$
\frac{d x}{d t}=k \cdot \mathrm{C}_{\mathrm{A}}^{m} \cdot \mathrm{C}_{\mathrm{B}}^{n}
$$

where $x$ is the change in the concentration $C$ in time $t$ and $k$ is the velocity constant. If $k$ is known, the changes in concentration for various initial concentrations of the reacting substances can be worked out by integrating the above equation, but the integration often absorbs valuable time. By choosing suitable quantities it is possible to plot curves which will apply generally to all reactions of a similar type. The author has worked out some of these, and puts them on record hoping that they may save much time and labour.

\section{Bi-molecular Reaction.}

If the reaction is bi-molecular of the type $A+B \rightarrow 1$ or more resultants, the reaction velocity is given by

$$
\frac{d x}{d t}=k(a-x)(b-x),
$$

where $a, b$ are the initial concentrations of $\mathrm{A}, \mathrm{B}$ respectively. The equation may be written

$$
\frac{d x}{d t}=k a^{2}\left(1-\frac{x^{2}}{a}\right)\left(\frac{b}{a}-\frac{x}{a}\right) \text {. }
$$

Putting $\frac{x}{a}=\mathrm{X}$, where $\mathrm{X}=$ fraction changed,

$$
\frac{d \mathrm{X}}{d t}=\mathrm{K}(1-\mathrm{X})(p-\mathrm{X}),
$$

where $\mathrm{K}=k a$ and $p=\frac{b}{a}$.

Take (i.) initial concentrations equal, i. e. $a=b$ or $p=1$, then

$$
\mathrm{K} t=\int_{0}^{\mathrm{x}} \frac{d \mathrm{X}}{(1-\overline{\mathrm{X}})^{2}}=\frac{\mathrm{X}}{1-\mathrm{X}} .
$$

* Communicated by the Author. 
The maximum value of $X=1$. Giving $X$ values up to 1 we get

$$
\begin{array}{llllllcccccc}
\mathrm{X} \ldots \ldots . & 0 & \cdot 1 & \cdot \mathbf{2} & \mathbf{3} & \cdot 4 & \cdot 5 & \cdot 6 & \cdot 7 & \cdot 8 & \cdot 9 & 1 \cdot 0 \\
\mathrm{~K} t \ldots \ldots & 0 & \cdot 111 & -250 & \cdot 428 & \cdot 666 & 1 \cdot 00 & 1 \cdot 50 & 2 \cdot 33 & 4 \cdot 00 & 9 \cdot 00 & \infty
\end{array}
$$

These are plotted on fig. $1(p=1)$, and the curve will apply to any bi-molecular reaction in which the initial

concentrations are equal.
Take (ii.) one of the substances in excess, say $\frac{b}{a}=p$, where $p>1$. Then we have

$p=1.5$.

$$
\mathrm{K} t=\frac{1}{1-p}\left\{\log _{e} \frac{p(1-\mathrm{X})}{p-\bar{X}}\right\} \text {. }
$$

$\begin{array}{cccccccccccccc}\mathrm{X} & \ldots & 0 & -1 & .2 & -3 & \cdot 4 & \cdot 5 & -6 & -7 & \cdot 8 & .9 & .95 & 1 \cdot 0\end{array}$

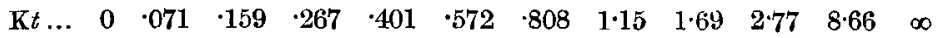
$p=\mathbf{2}$.

$\begin{array}{llllllllllllll}\mathrm{X} & \ldots & 0 & \cdot 1 & .2 & .3 & .4 & .5 & .6 & .7 & .8 & .9 & .95 & 1 \cdot 0\end{array}$

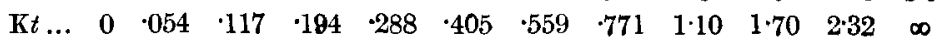
$p=3$.

$\begin{array}{lllllllllllllll}\mathrm{X} & \ldots & 0 & \cdot 1 & .2 & .3 & \cdot 4 & .5 & .6 & .7 & .8 & .9 & .94 & .97 & 1 \cdot 0\end{array}$ $\begin{array}{lllllllllllllll}\mathrm{K} t & \ldots & 0 & \cdot 036 & \cdot 077 & \cdot 126 & \cdot 183 & \cdot 255 & \cdot 344 & \cdot 386 & \cdot 549 & .851 & 1.09 & 1 \cdot 42 & \infty\end{array}$

These are plotted on fig. 1 (Pl. IX.), and the curves will apply to any bi-molecular reaction of the type $A+B \rightarrow 1$ or more resultants.

\section{Ter-molecular Reaction.}

Let the reaction be represented by $2 \mathrm{~A}+\mathrm{B} \rightarrow 1$ or more resultants, then the velocity of reaction is given by

$$
\begin{aligned}
\frac{d x}{d t} & =k(a-x)^{2}(b-x) \\
& =k a^{3}\left(1-\frac{x}{a}\right)^{2}\left(\frac{b}{a}-\frac{x}{a}\right) .
\end{aligned}
$$

Bringing to the same notation as before gives

where $\mathrm{K}=k a^{2}$.

$$
\mathrm{K} t=\int_{0}^{\mathrm{X}} \frac{d \mathrm{X}}{(1-\mathrm{X})^{2}(p-\overline{\mathrm{X}})^{2}}
$$

Take (i.) equal initial concentrations, i. e. $p=1$, then

which gives

$$
\mathrm{K} t=\int_{0}^{\mathrm{X}} \frac{d \mathrm{X}}{(1-\mathrm{X})^{3}}=\frac{1}{2} \frac{(2-\mathrm{X}) \mathrm{X}}{(1-\mathrm{X})^{2}},
$$

$$
\begin{aligned}
& \begin{array}{lllllllllllll}
\mathbf{X} \ldots \ldots & 0 & \cdot 1 & \cdot 2 & \cdot 3 & \cdot 4 & .5 & \cdot 6 & \cdot 7 & .8 & .9 & 1 \cdot 0
\end{array} \\
& \begin{array}{llllllllllll}
\mathrm{K} t \ldots \ldots & 0 & \cdot 117 & \cdot 281 & \cdot 520 & \cdot 889 & 1 \cdot 50 & 2 \cdot 63 & 5 \cdot 06 & 12 \cdot 0 & 50 & \infty
\end{array}
\end{aligned}
$$


These are plotted on figs. 2 and 3 , and the curve applies to any ter-molecular reaction in which the initial concentrations are equal.

Take (ii.) B in excess, i. e. $p=\frac{b}{a}>1$. We have

$$
\mathrm{K} t=\int_{0}^{\mathrm{X}} \frac{d \mathrm{X}}{(1-\mathrm{X})^{2}(p-\mathrm{X})}=\frac{1}{(1-p)^{2}}\left\{\log _{e} \frac{p(1-\mathrm{X})}{p-\mathrm{X}}-\frac{\mathrm{X}(1-p)}{1-\mathrm{X}}\right\} \text {, }
$$$$
p=1 \cdot 5 \text {. }
$$

$\begin{array}{lllllllccccc}\mathrm{X} \ldots \ldots . & 0 & \cdot 1 & \cdot 2 & \cdot 3 & \cdot 4 & \cdot 5 & \cdot 6 & 7 & .8 & \cdot 9 & 1 \cdot 0 \\ \mathrm{~K} t \ldots \ldots & 0 & \cdot 077 & \cdot 180 & \cdot 323 & \cdot 440 & \cdot 848 & 1 \cdot 38 & 2 \cdot 37 & 4 \cdot 62 & 12 \cdot 48 & \infty\end{array}$

$$
p=2 \text {. }
$$

$\begin{array}{lllllllllllll}\mathrm{X} \ldots \ldots . & 0 & \cdot 1 & .2 & .3 & \cdot 4 & .5 & .6 & .7 & .8 & .9 & 1.0\end{array}$

$\begin{array}{llllllllllll}\mathrm{K} t \ldots \ldots & 0 & \cdot 046 & \cdot 133 & \cdot 234 & \cdot 379 & \cdot 595 & \cdot 941 & 1 \cdot 56 & 2 \cdot 90 & 7.5 & \infty\end{array}$

$$
p=3 \text {. }
$$

$\begin{array}{ccccccccccccc}\mathrm{X} & \ldots \ldots & 0 & \cdot 1 & .2 & \cdot 3 & .4 & .5 & .6 & 7 & .8 & .9 & 1.0\end{array}$ $\begin{array}{lllllllllllll}\mathrm{K} t \ldots \ldots & 0 & \cdot 038 & \cdot 086 & \cdot 151 & \cdot 247 & \cdot 373 & \cdot 577 & \cdot 932 & 1 \cdot 68 & 4 \cdot 01 & \infty\end{array}$

$$
p=4 \text {. }
$$

$\begin{array}{llllllllllll}\mathrm{X} \ldots \ldots & 0 & \cdot 1 & -2 & -3 & \cdot 4 & .5 & .6 & -7 & -8 & .9 & 1.0\end{array}$

$\begin{array}{lllllllllllll}\mathrm{K} t \ldots \ldots & 0 & \cdot 028 & \cdot 064 & \cdot 111 & \cdot 177 & \cdot 274 & \cdot 416 & \cdot 665 & 1.07 & 2.7 & \infty\end{array}$

These figures and the graphs plotted from them (fig. 2) will apply to any ter-molecular reaction of the type $2 A+B \rightarrow 1$ or more resultants, $B$ being in excess.

Take (iii.) $\mathrm{A}$ in excess, and let $\frac{a}{b}=p>1$, then we have

$$
\mathrm{K} t=\int_{0}^{\mathrm{x}} \frac{d \mathrm{X}}{(p-\mathrm{X})^{2}(1-\mathrm{X})}=\frac{1}{(p-1)^{2}}\left\{\log _{e} \frac{p-\mathrm{X}}{p(1-\mathrm{X})}-\frac{\mathrm{X}(p-1)}{p(p-\mathrm{X})}\right\}
$$

where $\mathrm{K}=k t^{2}$.

$$
\begin{aligned}
& p=1 \text {. } \\
& \begin{array}{ccccccc}
\mathrm{X} \ldots \ldots \ldots . . & 0 & .4 & \cdot 7 & \cdot 8 & \cdot 9 & 1 \cdot 0 \\
\mathrm{~K} t \ldots \ldots \ldots & 0 & .576 & 2 \cdot 05 & 3 \cdot 69 & 8 \cdot 24 & \infty
\end{array} \\
& p=1 \frac{1}{2} . \\
& \begin{array}{cccccccccc}
\mathrm{X} \ldots \ldots \ldots & 0 & -1 & \cdot 2 & \cdot 5 & \cdot 7 & .8 & .9 & .94 & 1.0
\end{array} \\
& \begin{array}{llllllllll}
\mathrm{K} t \ldots \ldots \ldots . & 0 & -050 & -114 & \cdot 482 & 1 \cdot 13 & 1.85 & 3.51 & 6.02 & \infty
\end{array} \\
& p=2 \text {. } \\
& \begin{array}{lllllllllllll}
\mathrm{X} \ldots \ldots . & 0 & 1 & .2 & .3 & .4 & 5 & .7 & .9 & .95 & .97 & 1.0
\end{array} \\
& \begin{array}{lllllllllllll}
\hline k t \ldots . . & 0 & \cdot 027 & \cdot 062 & \cdot 110 & \cdot 162 & \cdot 239 & \cdot 503 & 1 \cdot 29 & 1 \cdot 87 & 2 \cdot 37 & \infty
\end{array} \\
& p=3 .
\end{aligned}
$$

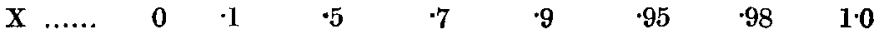

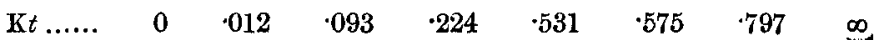


These figures and the corresponding graphs (fg. 3) apply to any ter-molecular reaction of the type $2 \mathrm{~A}+\mathrm{B} \rightarrow 1$ or more resultants, A being in excess.

\section{Quadri-molecular Reaction.}

Let the reaction be of the type $3 \mathrm{~A}+\mathrm{B} \rightarrow 1$ or more resultants, and let the initial concentrations be equal. The general equation is

$$
\begin{aligned}
\frac{d x}{d t} & =(a-x)^{3}(b-x) \\
& =k a^{4}\left(1-\frac{x}{a}\right)^{3}\left(\frac{b}{a}-\frac{x}{a}\right),
\end{aligned}
$$

when $\frac{b}{a}=1$

and $\mathrm{K}=k a^{3}$.

$$
\mathrm{K} t=\int_{0}^{\mathrm{x}} \frac{d \mathrm{X}}{(1-\mathrm{X})^{4}}=\frac{1}{3}\left\{\frac{1}{(1-\mathrm{X})^{3}}-1\right\},
$$

$$
\begin{array}{llllllcccrrr}
\mathbf{X} \ldots \ldots \ldots \ldots . . & 0 & \cdot 1 & \cdot 2 & \cdot 3 & \cdot 4 & \cdot 5 & \cdot 6 & 65 & \cdot 7 & 1 \cdot 0 \\
\mathbf{K} t & \ldots \ldots \ldots . . & 0 & \cdot 123 & \cdot 32 & \cdot 64 & 1 \cdot 21 & 2 \cdot 33 & 4 \cdot 87 & 7 \cdot 43 & 12 \cdot 0 & \infty
\end{array}
$$

Now take $\mathrm{B}$ in excess, putting $\frac{b}{a}=p>1$. The equation becomes

$$
\begin{gathered}
\mathrm{K} t=\int_{0}^{\mathrm{X}} \frac{d \mathrm{X}}{(1-\mathrm{X})^{3}(p-\mathrm{X})} \\
=-\mathrm{A} \log _{e}(1-\mathrm{X})+\mathrm{B} \frac{\mathrm{X}}{1-\mathrm{X}}+\frac{\mathrm{C}}{2}\left\{\frac{1}{(1-\mathrm{X})^{2}}-1\right\}+\mathrm{D} \log _{e} \frac{p}{p-\mathrm{X}},
\end{gathered}
$$

where $\mathrm{A}, \mathrm{B}, \mathrm{C}, \mathrm{D}$ are constants depending on the value of $p$.

$$
p=2 \text {. Then } \mathrm{A}=1 . \mathrm{B}=-1 . \mathrm{O}=1 . \mathrm{D}=-1 \text {. }
$$

$\begin{array}{cccccccc}\mathbf{X} \ldots \ldots \ldots . & 0 & \cdot 2 & .4 & .6 & 7 & 8 & 1 \cdot 0 \\ \mathrm{~K} t \ldots \ldots \ldots & 0 & \cdot 149 & .501 & \mathbf{1 . 6 8} & 3.49 & 9 \cdot 09 & \infty\end{array}$

$$
p=3 \text {. Then } \mathrm{A}=\frac{1}{8} . \quad \mathrm{B}=-\frac{1}{4} . \quad \mathrm{C}=\frac{1}{2} . \quad \mathrm{D}=-\frac{1}{8} .
$$

$\begin{array}{llllccrc}\mathrm{X} \ldots \ldots \ldots . & 0 & .3 & -5 & \cdot 7 & \cdot 8 & \cdot 9 & 1 \cdot 0 \\ \mathrm{~K} t \ldots \ldots \ldots & 0 & .184 & .564 & 2 \cdot 06 & 5 \cdot 16 & 22 \cdot 7 & \infty\end{array}$

$$
p=6 \text {. Then } \mathrm{A}=\frac{1}{125}, \quad \mathrm{~B}=-\frac{1}{25} . \quad \mathrm{C}=\frac{1}{5} . \quad \mathrm{D}=-\frac{1}{125} \text {. }
$$

$$
\begin{array}{ccccccc}
\mathrm{X} \ldots \ldots . & 0 & \cdot 5 & 7 & .8 & 9 & 1.0 \\
\mathrm{~K} t \ldots \ldots . & 0 & .265 & .925 & \mathbf{2 \cdot 2 5} & \mathbf{9 \cdot 5 2} & \infty
\end{array}
$$

These figures give the graphs (fig. 4) for a quadrimolecular reaction of the type $3 \mathrm{~A}+\mathrm{B} \rightarrow$, the substance $B$ being in excess. 
Now let the substance $\mathrm{A}$ be in excess, so that $\frac{a}{b}=p>1$. We have

where $\mathbf{K}=k b^{3} . \quad \mathbf{K} t=\int_{0}^{\mathbf{X}} \frac{d \mathrm{X}}{(p-\bar{X})^{3}(1-\mathbf{X})}$,

The solution is

$$
\begin{aligned}
\mathrm{K} t=-\mathrm{A} \log _{a} \frac{p-\mathrm{X}}{p} & +\mathrm{B} \frac{\mathrm{X}}{p(p-\overline{\mathrm{X}})} \\
& +\frac{\mathrm{C}}{2}\left\{\frac{1}{(p-\overline{\mathrm{X}})^{2}}-\frac{1}{p^{2}}\right\}-\mathrm{D} \log _{e}(1-\mathrm{X}),
\end{aligned}
$$

$\mathrm{A}, \mathrm{B}, \mathrm{C}, \mathrm{D}$ being constants depending on $p$.

$p=1$ it. Then $\mathrm{A}=-64 . \quad \mathrm{B}=-16 . \quad \mathrm{C}=\ldots 4 . \quad \mathrm{D}=64$.

$\begin{array}{lllllllll}\mathrm{X} & \ldots . . . . . . & 0 & \cdot 2 & .4 & 6 & .7 & .8 & 1.0\end{array}$

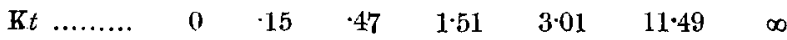

$p=1 \frac{1}{2}$. Then $\mathrm{A}=-8 . \quad \mathrm{B}=-4 . \quad \mathrm{C}=-2 . \quad \mathrm{D}=8$.

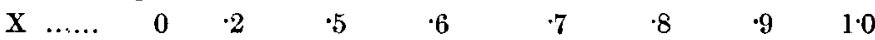

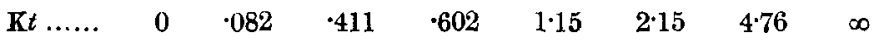

$p=2$. Then $\mathrm{A}=-1 . \quad \mathrm{B}=-1 . \quad \mathrm{O}=-1 . \quad \mathrm{D}=1$.

$\begin{array}{llllllllll}\mathbf{X} & \ldots . . . & 0 & .3 & .6 & .8 & .9 & .95 & .97 & 1.0\end{array}$

$\begin{array}{lllllllll}\mathrm{K} t \ldots . . . & 0 & .065 & .216 & .575 & 1.01 & 1.58 & 2.02 & \infty\end{array}$

The graphs for these are shown in fig. 5.

There is yet the quadri-molecular reaction of the type $2 \mathrm{~A}+2 \mathrm{~B} \rightarrow 1$ or more resultants. In this case we have

$$
\mathrm{K} t=\int_{0}^{\mathrm{X}} \frac{d \mathrm{X}}{(1-\mathrm{X})^{2}(p-\mathrm{X})^{2}},
$$

where $\mathrm{K}=k a^{3}$ and $p=\frac{b}{a}>1$.

The solution is

$$
\begin{aligned}
& \mathrm{K} t=\frac{2}{(p-1)^{3}} \log _{e} \frac{p(1-\mathrm{X})}{p-\mathrm{X}}+\frac{1}{(p-1)^{2}}\left\{\frac{p+1-2 \mathrm{X}}{(1-\mathrm{X})(p-\mathrm{X})}-\frac{p+1}{p}\right\} \text {. } \\
& p=1 \text {. } \\
& \begin{array}{rcccrrrr}
\mathrm{X} \ldots \ldots \ldots . & 0 & \cdot 2 & \cdot 4 & 6 & \cdot 7 & \cdot 8 & 1 \cdot 0 \\
\mathrm{~K} t \ldots \ldots \ldots . & 0 & \cdot 21 & \cdot 70 & 2 \cdot 2 & 4 \cdot 7 & 11 \cdot 7 & \infty
\end{array} \\
& p=2 .
\end{aligned}
$$

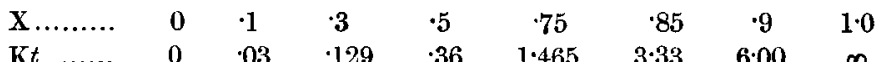

$$
\begin{aligned}
& \begin{array}{llllllllll}
\mathrm{K} t & \ldots . . . & 0 & .03 & \cdot 129 & .36 & 1 \cdot 465 & 3.33 & 6.00 & \infty
\end{array} \\
& p=3 . \\
& \begin{array}{llllcrr}
\mathrm{X} \ldots \ldots . & 0 & .5 & .8 & .9 & .95 & 1.0 \\
\mathrm{~K} t \ldots \ldots & \mathbf{0} & .141 & .707 & 1.80 & 4.14 & \infty
\end{array}
\end{aligned}
$$

The general curves for this type of quadri-molecular reaction are shown in fig. 6 .

Phil. Mag. S. 6. Vol. 35. No. 207. March 1918. X 


\section{Application of the Curves.}

(i.) To find the velocity coefficient $k$.

When the order of the reaction and the initial concentrations are known we have only to measure the fraction (X) changed in a given time $t$ in order to find $\mathrm{K} t$ from the curve and therefore $k$.

(ii.) To find the fraction (X) changed in a given time $t$.

This requires a knowledge of $k$, the order of the reaction, and the initial concentrations. Then $\mathrm{X}$ for a given $t$ can be read straight from the curve.

(iii.) To find the Order of a reaction.

Two or more determinations of $\mathrm{X}$ and $t$ are needed together with a knowledge of the initial concentratious. The particular curve on which the points $(\mathrm{X}, t)$ best lie, determines the order of the reaction.

London,

December 1917.

XXXII. On the Coefficients of Potential of Two Conducting Spheres. By Prof. A. Andenson *.

T $T$ may be of interest to show how the coefficients of 1 potential of two conducting spheres may be obtained directly without a previous determination of the coefficients of capacity and induction, and without making use of electric images. For this purpose the following elementary proposition, which is easily seen to be true, may be used.

If a conducting sphere whose radius is a have a charge $\mathrm{E}$, and if other charged bodies be brought into the field, the potential $\mathrm{V}$ of the charge $\mathrm{E}$ at an external point $\mathrm{P}$ whose distance from the centre of the sphere is $r$ will be given by the equation

$$
r \mathrm{~V}=\mathrm{E}+a\left(\mathrm{U}-\mathrm{U}^{\prime}\right),
$$

where $U$ is the potential at the centre of the sphere of the introduced charges, and $U^{\prime}$ their potential at $\mathrm{P}^{\prime}$, the inverse point of $\mathrm{P}$ in the sphere.

Let $A$ and $B$ be the centres of two spheres whose radii are $a$ and $b$, the distance $A B$ heing $c$. Tet $I_{1}$ be the inverse point of $A$ in the spliere $B, I_{2}$ the inverse of $I_{1}$ in $A, I_{3}$ the inverse of $I_{2}$ in $B$, and so on. Also, let $J_{1}$ be the inverse of $B$ in the sphere $A, J_{2}$ the inverse of $J_{1}$ in $B, J_{3}$ the inverse of $J_{2}$ in $A$, and so on.

Let $\mathrm{U}$ be the potential of the sphere $\mathrm{A}$ at $\mathrm{B}, \mathrm{U}_{1}, \mathrm{U}_{2}, \mathrm{U}_{3}$, \&c. its potentials at $\mathrm{I}_{1}, \mathrm{I}_{2}, \mathrm{I}_{3}$, \&c., and $\mathrm{U}_{1}^{\prime}, \mathrm{U}_{2}{ }^{\prime}, \mathrm{U}_{3}^{\prime}$, \&c. its potentials at $\mathrm{J}_{1}, \mathrm{~J}_{2}, \mathrm{~J}_{3}, \& c_{\text {. }}$ Also, let $\mathrm{V}$ be the potential of the sphere $B$ at $A, V_{1}, V_{2}, V_{3}, \&$ c. its potentials at $I_{1}, I_{2}, I_{3}$, * Communicated by the Author. 

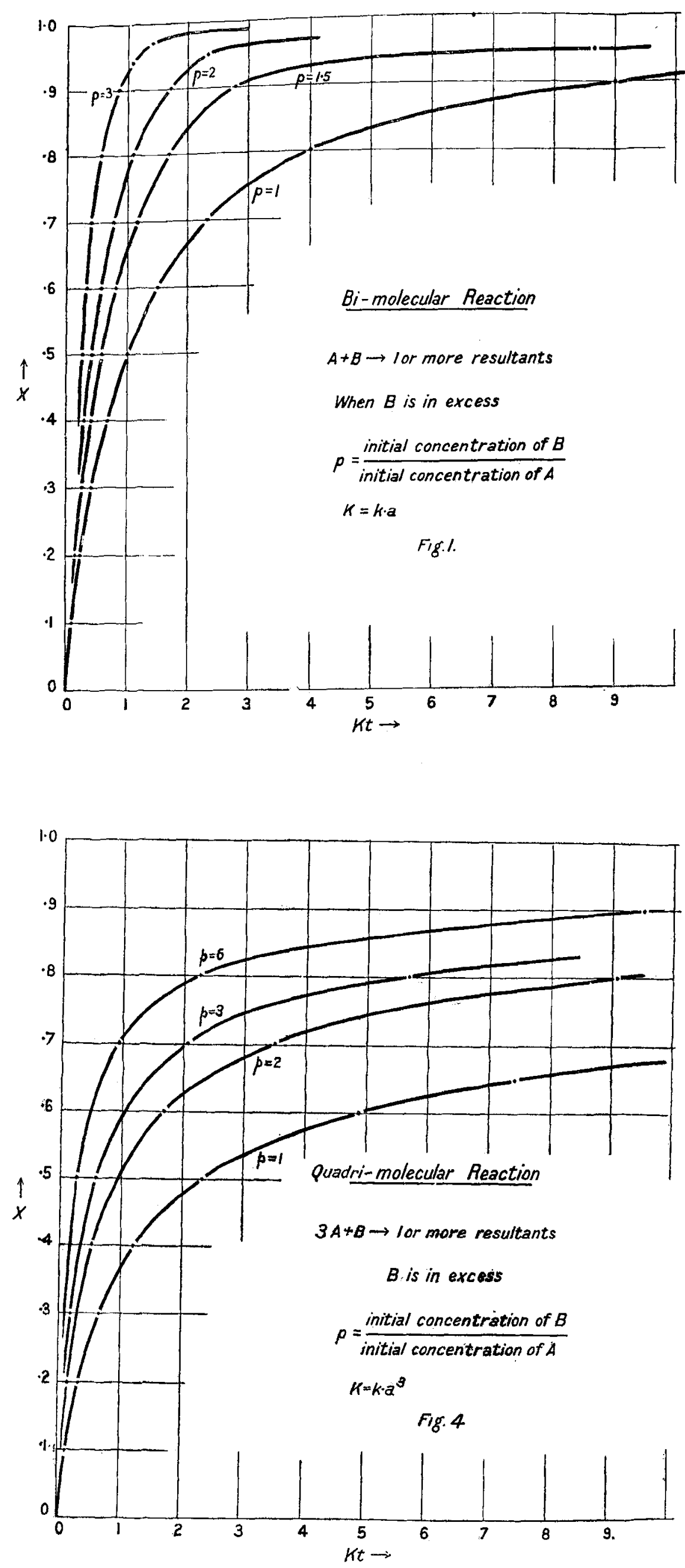
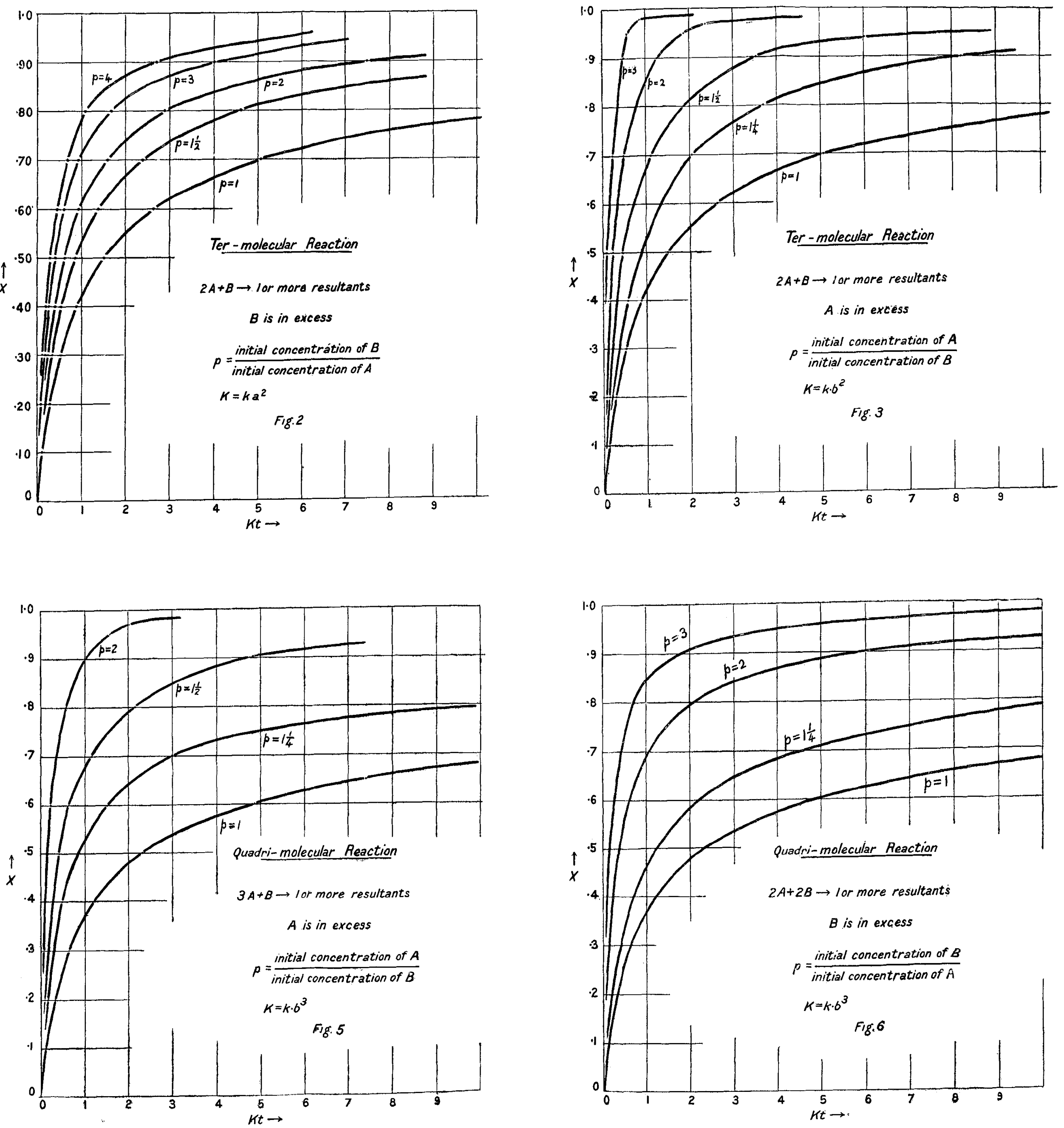